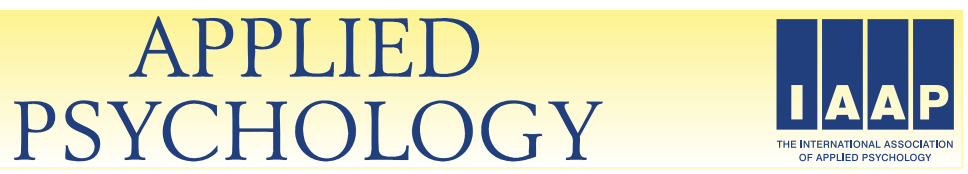

APPLIED PSYCHOLOGY: AN INTERNATIONAL REVIEW, 2018, 67 (1), 3-29 doi: 10.1111/apps. 12110

\title{
How Colleagues Can Support Each Other's Needs and Motivation: An Intervention on Employee Work Motivation
}

\author{
Tomas Jungert* \\ Lund University, Sweden
}

Anja Van den Broeck

KU Leuven, Belgium and North West University, South Africa

Bert Schreurs

Maastricht University School of Business and Economics, Maastricht, Netherlands

Ulla Osterman

Orangino Work, Sweden

\begin{abstract}
Organisations have flattened and increasingly rely on teamwork. Therefore, colleagues play an increasingly important role in stimulating employee motivation. Adopting Self-Determination Theory as a guiding framework, the aim of this field experiment was to examine whether team members can be trained in supporting each other's basic psychological needs for autonomy, competence, and relatedness and, hence, increase each other's need satisfaction and autonomous motivation, while decreasing controlled motivation. We delivered training to 146 participants nested in 26 participating teams and assessed basic need satisfaction and autonomous and controlled motivation before and after the intervention. Multilevel regression analyses indicated that employees in the experimental (i.e. intervention) condition had a stronger increase in need satisfaction and autonomous motivation than employees did in the control condition, and that the increase in autonomous motivation was mediated by an increase in need satisfaction. This study provides added value for theory on need satisfaction and demonstrates that a relatively brief intervention among team members may be effective in creating employee need support and increasing autonomous motivation.
\end{abstract}

* Address for correspondence: Tomas Jungert, Lund University, Box 213, SE-221 00 Lund, Sweden. Email: tomas.jungert@psy.lu.se.

$\dagger$ Note: The first two authors contributed equally to this manuscript. 


\section{INTRODUCTION}

Having a well-functioning workforce is essential for organisations to stay competitive. Employee motivation is essential for such organisational success. According to Self-Determination Theory (SDT; Deci \& Ryan, 2000; Gagné \& Deci, 2005) employees feel and perform better when their motivation is autonomous in nature, that is, when they volitionally engage in their work because they find it enjoyable, interesting or valuable. Employees function less optimally when they are motivated in a controlled way and engage in particular behaviour out of inner or external pressures. Because of the importance of autonomous versus controlled motivation for employee behaviour and wellbeing, it is crucial to understand when both types of motivation emerge. According to SDT, employees become autonomously motivated when they feel satisfied in their basic psychological needs for autonomy, competence and relatedness, while controlled motivation arises when these needs remain unsatisfied. The current study aims to test this assumption through an intervention study. Specifically, we present a field experiment investigating the effect of a 'need support' intervention on employees' levels of need satisfaction, and autonomous and controlled motivation. In the intervention, which was administered in a group setting, employees are trained to support each other's basic psychological needs. Based on tenets from SDT, we expect employees that took part in the intervention to show higher levels of need satisfaction and autonomous motivation, and lower levels of controlled motivation than employees who were part of the control group.

This study makes several contributions to the literature. First, this study expands on the literature on the antecedents of basic need satisfaction and autonomous versus controlled motivation by focusing on the role of peers. Although need satisfaction and the resulting types of motivation are said to arise from both environmental and social aspects (Gagné \& Deci, 2005), most evidence focuses on the role of organisational (e.g. organisational support) and job-related (e.g. job demands) antecedents of need satisfaction, which are more structural in nature (Van den Broeck, Ferris, Chang, \& Rosen, 2016). When considering social antecedents, scholars have focused on supervisory or leader support (e.g. leadership styles, LMX). Although some evidence suggests that colleagues may play an important role (Jungert, Koestner, Houlfort, \& Schattke, 2013; Moreau \& Mageau, 2012), support from colleagues is mostly regarded as one of the many job characteristics influencing employee motivation (Van den Broeck et al., 2016). The current study aims to do justice to the importance of the role of peers as a social antecedent of need satisfaction and, hence, autonomous versus controlled motivation. Such an approach is warranted, given that organisations increasingly rely on teams of colleagues rather than managers to make organisations work. 
The focus on team members, colleagues or peers also allows us to broaden the scope of interventions on need supportive behaviour. Although anyone can be need supportive in interacting with others (Rocchi, Pelletier, Cheung, Baxter, \& Beaudry, 2017), a thorough analysis of the literature learns that intervention studies to increase need supportive behaviour are mostly targeted at socialising agents in a hierarchical position such as teachers, parents or managers (Su \& Reeve, 2011). Oftentimes these interventions capitalise on multiple knowledge and activity-based sessions explaining the theoretical foundations of SDT and need supportive behaviour, and exercising such behaviour in complementary practical sessions using individualised feedback on one's own need supportive behaviour, either in role play or real life situations (e.g. Aelterman, Vansteenkiste, Van Keer, \& Haerens, 2016; Reeve \& Cheon, 2016). Such interventions are effective (Su \& Reeve, 2011), but also expensive, as they require expert coaches to teach the trainees and/or imply considerable time off for the trainees (e.g. Deci, Connell, \& Ryan, 1989). The intervention tested in this study takes a different approach and examines how members belonging to the same work team can learn how to satisfy each other's needs and support autonomous versus controlled motivation through exercises on taking each other's perspective, communication, and collaboration with minimal support from HR and their supervisors.

Using a quasi-experimental method also allows to answer the recent call for the use of more advanced methodologies to understand need satisfaction at work (Van den Broeck et al., 2016). To date, insights into how to increase employee need satisfaction and the resulting types of motivation are mostly concluded from cross-sectional studies, whereas quasi-experimental methods are needed to draw such causal conclusions (Grant \& Wall, 2009). Moreover, we adopt an intra-individual approach, rather than an inter-individual approach. Instead of focusing on differences between people, we thus test whether we can change-through the intervention-how each and every employee can feel more satisfied in his/her needs, feel more autonomous and less controlled in his/her motivation, and whether such differences are, on average, different from the employees in the control group who did not participate in the intervention (Le Blanc, Hox, Schaufeli, Taris, \& Peeters, 2007). This study also has practical merits as it helps practitioners in designing straightforward interventions intended to enhance employee motivation in a team setting. Before detailing the intervention, in the following paragraphs we describe autonomous and controlled motivation and need satisfaction from the perspective of SDT.

\section{Autonomous and Controlled Motivation}

Self-determination Theory (SDT) started off by differentiating intrinsic from extrinsic motivation (Deci \& Ryan, 1985). While intrinsically motivated 
behaviour is driven by inherent interest or pleasure in the activity, extrinsic motivation pertains to engaging in a particular behaviour because one wants to obtain foreseeable separable consequences. Further developments in SDT suggests that extrinsic motivation should not be seen as a unitary construct, but needs to be divided into five distinct subtypes, depending on the kind of consequences that are linked to the behaviour (Deci \& Ryan, 2000). The first subtype, external regulation reflects motivation to receive external rewards or avoid threats. For example, employees may work late to finish a project only because they expect to get a raise or a bonus or avoid criticism from their boss. The second subtype, introjected regulation, is characterised by rewarding or punishing oneself. Employees may make their self-worth contingent upon completing a particular task or feel pride, guilt or shame when (not) engaging in a particular behaviour. For example, employees could work late to avoid feeling guilty not working. Finally, identified regulation involves a conscious valuing of the activity and a self-endorsement of goals. Identified employees engage in particular behaviour because they consider it important or valuable. For example, employees may want to work late to finish a project because they understand how important the project is for the company or the customer.

The different types of extrinsic motivation reflect different degrees of internalisation or the degree to which people have endorsed the reason why they engage in a particular behaviour. While external regulation reflects the type of motivation in which the extrinsic reason for doing the behaviour is completely external, in case of introjection the reason for the behaviour is partially integrated. When acting out of introjected motivation, employees are not motivated because of rewards or punishments administered by others, but because they put themselves under pressure. External regulation and introjection are therefore characterised by feelings of being controlled - either by others or by oneself - and grouped under controlled motivation (Deci \& Ryan, 2000).

Identification, in contrast, is considered to be an internalised type of motivation. In the case of identification, employees fully endorse the extrinsic reasons for their behaviour and have integrated these reasons as part of their sense of self. As such, it is similar to intrinsic motivation, which emerges from one's interaction with the task and is therefore completely internal. Because they are characterised by an internal locus of control, identification and intrinsic motivation can be grouped as autonomous motivation. To date, SDT scholars consider the differentiation between controlled and autonomous motivation as most crucial: while autonomous motivation is expected to lead to a host of desirable outcomes, controlled motivation does not have such beneficial effects and may even lead to unwanted outcomes (Deci \& Ryan, 2000; Gagné \& Deci, 2005).

In line with this assumption, research shows that autonomous motivation at work is related to important organisational and individual outcomes. For example, autonomous motivation affects performance: it has been related to 
higher levels of effort (De Cooman, Stynen, Van den Broeck, Sels, \& De Witte, 2013), persistence (Deci \& Ryan, 2008), in-role performance (Moran, Diefendorff, Kim, \& Liu, 2012), learning (Roth, Assor, Kanat-Maymon, \& Kaplan, 2007), creativity (Grant \& Berry, 2011), as well as to lower turnover intentions (Williams, Halvari, Niemiec, Sørebø, Olafsen, \& Westbye, 2014). Autonomous motivation has furthermore been associated with aspects of wellbeing, such as higher engagement and work satisfaction (Gillet, Gagné, Sauvagère, \& Fouquereau, 2013; Van den Broeck, Lens, De Witte, \& Van Coillie, 2013) and less emotional exhaustion and burnout (Van den Broeck et al., 2013) and more effective coping (Deci \& Ryan, 2008; Julien, Senécal, \& Guay, 2009). In contrast, controlled motivation has not been found to be highly related to any of these outcomes, and may even have negative implications for employee performance and well-being (see Chemolli, Gagné, \& Koestner, 2012; Gagné et al., 2015).

From this overview it becomes evident that autonomous motivation is a significant advantage for employees and organisations alike, while controlled motivation should be avoided. Hence, it becomes crucial to understand how autonomous motivation can be fostered and controlled motivation can be decreased. In SDT, satisfaction of three basic needs is considered a prerequisite for autonomous motivation, while it also has the potential to offset controlled motivation (Gagné \& Deci, 2005; Ryan \& Deci, 2000).

\section{Basic Need Satisfaction}

Within SDT, three basic needs are considered to be crucial, that is, the need for autonomy, competence, and relatedness. These needs are said to be as essential for optimal psychological functioning as much as water, food and shelter are for our physical health (Deci \& Ryan, 2000). The need for autonomy is defined as individuals' desire to behave in line with their own interests, to make their own choices, to express their feelings freely and to initiate their own actions. The need for autonomy is about volition, and should not be equated with independence (Ryan, 1995): independent employees are not influenced by managers or co-workers and stick to their own agenda, but employees who have satisfied the need for autonomy may volitionally follow the requests of others as long as they feel psychologically free in endorsing these requests (Van den Broeck, Vansteenkiste, De Witte, Soenens, \& Lens, 2010a).

The need for competence refers to an individual's sense of being effective and sense of mastery (Deci \& Ryan, 2000). When people are allowed to engage in challenging tasks to develop their skills and when they can adapt to complex and changing environments, their need for competence is satisfied. Finally, the need for relatedness entails the wish to have caring bonds and positive alliances with others (Baumeister \& Leary, 1995; Deci \& Ryan, 2000). The need for relatedness refers to one's need to feel connected to others and to care and to 
be cared for. Enjoyable interactions with colleagues and superiors will satisfy this need.

Meta-analytic evidence provides support for the expected positive effects of basic need satisfaction (Van den Broeck et al., 2016). For example, need satisfaction is related to higher performance (Baard, Deci, \& Ryan, 2004), higher organisational commitment (Gagné, Chemolli, Forest, \& Koestner, 2008), more job satisfaction (Van den Broeck, Vansteenkiste, Lens, \& De Witte, 2010b), and lower incidence of burnout (Van den Broeck, Vansteenkiste, De Witte, \& Lens, 2008). Satisfaction of the basic needs associates with autonomous motivation, while it may offset more controlled types of motivation (Van den Broeck et al., 2016). In general, although the needs cannot be reduced to one another, they each seem to have similar effects and many studies examine need satisfaction as an aggregate combining all three needs (Van den Broeck et al., 2016).

The antecedents of basic need satisfaction have been widely studied (Van den Broeck et al., 2016). Need satisfaction has been found to arise from high quality job design, including having many job resources (e.g. task significance, opportunities for skill utilisation) and not too many job demands (e.g. politics, role conflict). Need satisfaction may furthermore also stem from HR practices such as training and organisational factors including organisational support, justice and person-organisational fit. The basic needs are furthermore satisfied by leader support, transformational and authentic leaderships, while abusive supervision frustrates the basic needs. In studying the antecedents of need satisfaction, research has mostly focused on the structural aspects in the immediate job, the broader organisational context, as well as social influences in terms of leadership styles and behaviour.

What is lacking, however, is a clear understanding of how colleagues working in the same team may help to increase the satisfaction of basic needs. Gaining understanding in how colleagues within teams may support each other's need satisfaction and motivation becomes increasingly important because of at least two reasons. First, organisations are becoming flatter and the number of managers is decreasing. This leaves the remaining managers with a bigger span of control, and less opportunities and time to support, coach and motivate their employees. Research shows that under the condition of a larger span of control employees are less committed, unless they receive support from elsewhere (Gittell, 2001). Parallel to the decrease of managerial influence on employees, the impact of team members is on the rise. Teams play a role in most organisations' operations, as organisations generally rely on small teams to perform well, often without close managerial supervision (Cordery, Morrison, Wright, \& Wall, 2010; Zellmer-Bruhn, 2003), and to the satisfaction of individual employees (Roth, Markova, Monsur, \& Severson, 2009). Because of the increasing importance of teams for employee performance and wellbeing, it becomes imperative to study the extent to which team members can be 
trained to satisfy each other's needs and support each other's autonomous motivation and decrease controlled motivation.

\section{Perspective Taking, Communication and Collaboration as Antecedents of Need Satisfaction}

In this study, we examine the effect of a team-based intervention designed to improve team members' perspective taking, communication and collaboration skills. This intervention helps each individual team member to support each of his/her colleagues' needs such that they become more satisfied in their needs for autonomy, competence and relatedness, and therefore also feel more autonomously motivated and less controlled, compared to employees in the teams which do not receive such training.

Need support consists of different elements, but there is no consensus on which elements should be included (Rocchi et al., 2017). Yet, most of the proposed elements are suggested to be highly interrelated and synergistic in supporting each of the basic needs (Cheon, Reeve, Yu, \& Jang, 2014). Within the domain of work, perspective taking is considered key (Gagné \& Deci 2005), as ultimately people need to understand the perspective of others to identify, nurture and develop their inner motivational resources (i.e. preferences, values and interests), which is the goal of need support (Reeve \& Jang, 2006). As interventions are considered most effective when a broad range of supportive behaviours is included (Su \& Reeve, 2011), next to perspective taking, we also focused on improving communication and collaboration skills among employees to increase their ability to support each other's needs and, hence, their autonomous versus controlled motivation. Regardless of which need is at stake, communication and collaboration are essential vehicles to express need support (Langdon, Schlote, Melton, \& Tessier, 2017).

Team members were trained in sharing information about themselves and encouraged to actively listen to each other and discuss similarities and differences in perspectives. Using open communication, by making assumptions explicit and engaging in constructive dialogue, they were given the opportunity to get to know each other as a person, which is an essential aspect of need support, even among young children (Côté-Lecaldare, Joussemet, \& Dufour, 2016). Furthermore, team members were encouraged to use informational, rather than pressuring language, which helped them to gain insight in each other's perspectives. Understanding each other then helps to provide choices and rationales that are meaningful to the others and therefore allows supporting their need for autonomy (Reeve \& Cheon, 2016).

Discussing collaboration further allowed team members to display specific behaviours known to be need supportive (Rocchi et al., 2017). For example, team members practised providing constructive and valuable feedback; they were encouraged to discuss how each of the team members could contribute to 
achieving team goals; they identified areas for personal growth and development; and shared ideas about how each of them could be effective, all of which contribute to competence satisfaction. Finally, during the intervention, employees were instructed to take time to listen and signal they were genuinely interested in each other. They were empathic and supportive rather than evaluative or rejecting, supporting relatedness satisfaction (Rocchi et al., 2017).

Hence, the intervention is designed to train employees to take each other's perspective, and to communicate and collaborate well. Consequently, within the participating teams, all employees are expected to feel more satisfied in their needs and become more autonomous and less controlled in their motivation. This is because the training in perspective taking, communication and collaboration is expected to make each of the team members supportive of the other team members' needs, which would then result in the need satisfaction and optimal motivation of the other team members (Jungert et al., 2013; Moreau \& Mageau, 2012). Notably, being need supportive towards others also helps to satisfy one's own needs and to improve one's own motivation (Cheon et al., 2014), potentially because the effects of need support (e.g. in terms of increased engagement among those being supported) further fuels need supportive behaviour (Van den Berghe, Cardon, Tallir, Kirk, \& Haerens, 2016).

In short, we hypothesise that employees of the teams participating in the intervention will experience higher satisfaction of the three basic psychological needs at the follow up, which will not be the case for employees of the teams in the control group, who do not receive a specific intervention. In addition, in line with SDT, we also expect that via increased basic psychological need satisfaction, members of the intervention group will report increased levels of autonomous work motivation, and decreased levels of controlled work motivation after the intervention compared to before. No such changes in motivation are expected for members of the control group.

Hypothesis 1: Employees participating in the intervention will experience increases in basic need satisfaction, which in turn increases autonomous motivation, while no such changes occur in employees that are part of the control group.

Hypothesis 2: Employees participating in the intervention will experience increases in basic need satisfaction, which in turn decreases controlled motivation, while no such changes occur for employees that are part of the control group.

\section{METHOD}

\section{Participants and Procedure}

The field-experimental design of this study consisted of pretest and follow-up measurements among a sample of 211 employees working in 29 teams of three 
organisations in the banking and property sector in northern Europe. The participants worked with issues such as consultancy, global finance, business support operations, and wealth management. The intervention was carried out at the individual level in a team context. Data were solicited from 22 teams participating in the intervention (i.e. experimental teams), while 7 teams served as control group (i.e. control teams). Both experimental and control teams were existing work teams. They were similar in size and members of the experimental and control teams had similar functional backgrounds. The experimental teams participated in an intervention including two half-day workshops facilitated by trained HR employees, and three self-conducted feedback training sessions among team members, without any external facilitators. The workshops and sessions took place during the course of about 7 weeks.

All team members were invited to complete a web-based survey at Time 1, in February to March (2 to 3 weeks before the intervention) and at Time 2, in March to April (a week after the intervention was completed). Participation was voluntary and respondents were assured confidentiality of their responses. The intervention was carried out during working hours, as was the completion of the surveys. In each of the organisations, the intervention was enabled by the management and team leaders, which, for example, granted enough time to carry out the intervention.

In total, 242 surveys were distributed in the first wave (183 to members of experimental teams and 59 to members of control teams), of which 211 (168 from members in experimental teams and 43 from members in control teams) were completed. This led to an overall response rate of 87.20 per cent at Time 1. Due to communication problems, three teams did not fill in the questionnaire at Time 2 ( $N=11$ from two teams in one organisation and $N=7$ from one team in the other organisation). Thus, the final number of participating teams was 26, including 146 participants (112 from 19 experimental teams and 34 from seven control teams). This is visualised in the flow diagram in Figure 1.

The mean size of the experimental teams was $9.41(S D=2.64)$, ranging from 6 to 14 members. The average age of participants was $45.14(S D=8.48)$ years. On average, the participants in the experimental teams had been working in their current organisations for $12.38(S D=9.04)$ years and in their current teams for $2.82(S D=2.50)$ years. In total 76 per cent were female. The mean size of the control teams was $9.25(S D=2.99)$, ranging from 6 to 13 members. The average age of the participants in the control teams was $46.49(S D=11.73)$ years. On average, these participants had been working in their current organisations for $15.62(S D=11.72)$ years, and in their current teams for 6.67 $(S D=4.34)$ years. In total, 59 per cent were female. There was no significant difference in participants' age, $t(50.83)=-0.61, n s(d=-0.12)$, education, $t(209)=0.21$, $n s \quad(d=0.04)$, and work experience, $t(51.13)=-1.64$, ns $(d=-0.34)$ between the experimental and control groups. 


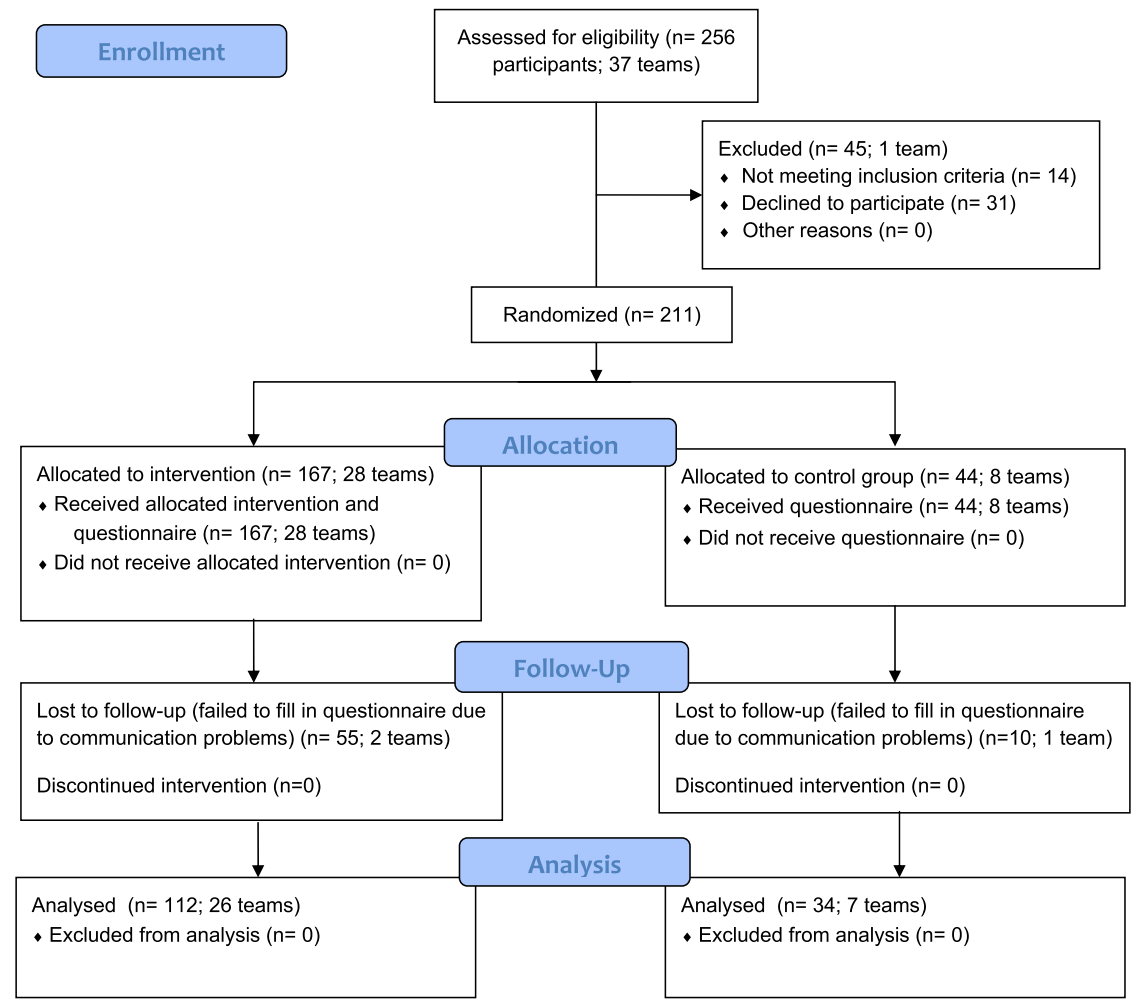

FIGURE 1. Flow diagram of participants and team [Colour figure can be viewed at wileyonlinelibrary.com]

\section{The Need Support Intervention}

The focus of the intervention was on perspective taking, communication, and collaboration among the team members and aimed at fostering their psychological needs and subsequent autonomous versus controlled work motivation. To start the dialogues among team members, we provided 15 cards including work behaviours or definitions, such as Committed - "I stand behind decisions made and take full responsibility for them"; Solution focused - "I concentrate more on solutions than on problems"; Knowledge sharer-"I willingly share my skills and knowledge with others". The team members reflected, took standpoints, and discussed about how they perceived themselves and the team concerning various behaviours and definitions. For example, if one participant picked the card "team building", he/she described how this behaviour characterised him or her. After listening carefully and with an open mind, other team members could then share how they perceived the other team member and 
themselves as being team builders, which resulted in an open discussion on team building in the team. These discussions foster perspective taking (i.e. all team members try to see how each team member views him or herself and the other team members), communication skills (i.e. employees need to express their own viewpoints, listen actively to each other) and collaboration (i.e. they discuss how they can collaborate taking into account each other's personal characteristics).

The control teams did not receive any special training during the research period. They were informed to pay attention to how they collaborated and communicated among each other. In addition, we informed the control teams that they would be able to participate in the intervention later on in the current year, and by the end of the year, all teams had taken part in the intervention.

\section{Measurements}

Basic need satisfaction was measured using the Basic Psychological Needs at Work Scale (BPNWS; Brien, Forest, Mageau, Boudrias, Desrumaux, Brunet, $\&$ Morin, 2012). This scale consists of 11 items designed to measure the degree to which employees feel supported in their basic psychological needs at work. The scale is composed of three subscales, tapping into satisfaction of the needs for autonomy (e.g. "I am free to express my ideas and opinions in my team"), competence (e.g. "I feel competent at work"), and need for relatedness (e.g. "When I'm with the people from my work environment, I feel understood"). All items were rated on a 7 -point scale (from $1=$ very true to $7=$ not at all true). Internal consistency coefficients for autonomy $(\alpha=.64$ at Time 1 , $\alpha=.70$ at Time 2$)$, competence ( $\alpha=.70$ at Time $1, \alpha=.69$ at Time 2 ), and relatedness $(\alpha=.85$ at Time $1, \alpha=.55$ at Time 2$)$ evidenced low internal consistency for some of the subscales. Therefore, we decided to proceed with general need satisfaction using all 11 items, which had acceptable alpha values $(\alpha=.86$ at Time $1, \alpha=.76$ at Time 2 ).

Autonomous and controlled motivation were measured using the Multidimensional Work Motivation Scale (MWMS; Gagné et al., 2015). This scale consists of 16 items measuring the four types of motivation. All items are rated on a 7 -point scale (from $1=$ very true to $7=$ not at all true). The scale taps into external regulation (e.g. "Because others will reward me financially only if I put enough effort in my job (e.g., employer, supervisor, ...”), introjected regulation (e.g. "Because otherwise I will feel bad about myself"), identified regulation (e.g. "Because I personally consider it important to put efforts in this job"), as well as intrinsic motivation (e.g. "Because what I do in my work is exciting"). The items of external regulation and introjected regulation were grouped into controlled motivation. The items of the identified regulation and intrinsic motivation refer to autonomous motivation. Internal consistency coefficients for autonomous motivation $(\alpha=.84$ at Time 1 , and $\alpha=.85$ at 
Time 2), and controlled motivation ( $\alpha=.78$ at Time 1 , and $\alpha=.79$ at Time 2$)$ were satisfactory.

Demographics. Participants also indicated their age, education, gender, and tenure in their current organisation and in their current team. No differences in motivation were found for any of these background variables, except for gender: There were significant gender differences ${ }^{1}$ on controlled motivation at Time 1, with women $(M=4.79)$ having higher levels of controlled motivation than men $(M=4.35), t(209)=3.40, p<.01, d=0.49$.

\section{Data Analysis Approach}

To test the hypotheses, we adopted a similar approach as Le Blanc et al. (2007). Because of the pre-post intervention research design, our data have a nested structure with measurement occasions nested within individuals. Accordingly, we use multilevel regression analysis (STATA 12.0) to investigate the effect the intervention has on basic need satisfaction and subsequent autonomous and controlled motivation. In contrast to other methods for analysing longitudinal data (e.g. repeated-measures analysis of variance), multilevel regression analysis does not require list-wise deletion of missing data but uses all available information. Furthermore, multilevel modelling accounts for the dependent nature of the measurements at the lower level and results in a more accurate test of significance, since it corrects for the standard error associated with its estimation (Hox, 2010; Krull \& MacKinnon, 2001).

In addition to the occasions-within-individuals nesting, individuals were also nested within teams. Therefore, the main analysis model is a three-level regression model, with successive measurement occasions (pre-post) nested within individuals, who are nested within teams. ${ }^{2}$ In order to establish mediation, the multi-level mediation testing procedure with bootstrapping recommended by Krull and MacKinnon (1999, 2001) was applied.

\section{RESULTS}

\section{Preliminary Analyses}

Table 1 presents, separately for the experimental and control groups, the means and standard deviations for each of the variables at each measurement at the individual level, and Table 2 presents their intercorrelations for the two

${ }^{1}$ We carried out the analyses with and without gender and gender balance as control variables. Adding gender and/or gender balance as controls did not change any of the findings. For reasons of parsimony and power, we report the findings without controls.

${ }^{2}$ Strictly speaking, the data have a four-level structure since teams are also nested within organisations. Because almost no variance resided at the organisational level we decided to not account for the organisational level.

(C) 2017 International Association of Applied Psychology. 


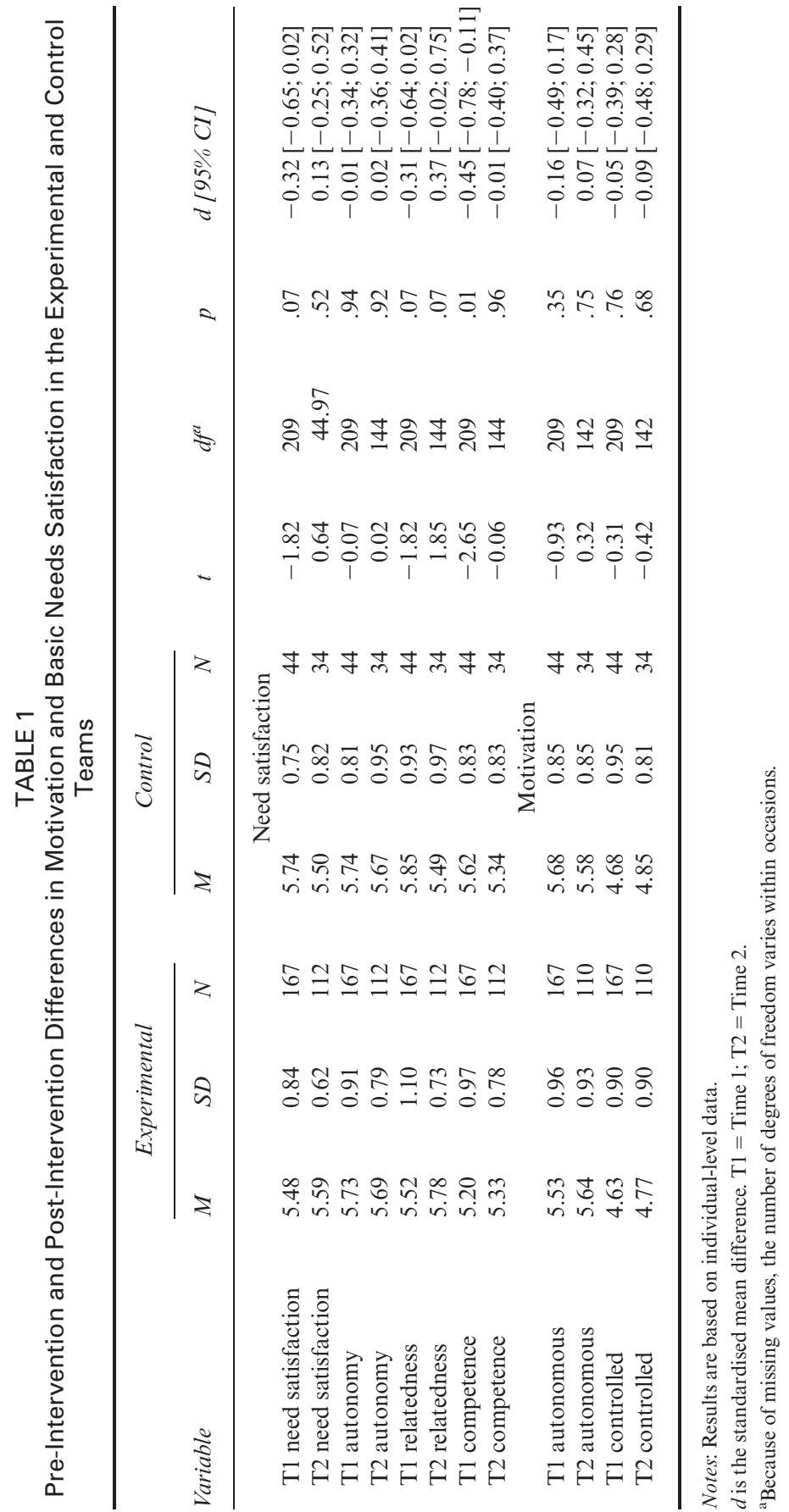


TABLE 2

Intercorrelations among the Study Variables at the Two Measurement Occasions

\begin{tabular}{lccccccccc}
\hline & 1 & 2 & 3 & 4 & 5 & 6 & 7 & 8 & 9 \\
\hline 1 Need satisfaction1 & - & $.30^{* *}$ & $.30^{* *}$ & $.22^{*}$ & .06 & .05 & $.23^{* *}$ & .13 & .01 \\
2 Need satisfaction2 & $.51^{* *}$ & - & .09 & .04 & .06 & .06 & .16 & .08 & .16 \\
3 Autonomous mot1 & $.45^{* *}$ & .03 & - & $.78^{* *}$ & $.44^{* *}$ & $.47^{* *}$ & .10 & .04 & -.12 \\
4 Autonomous mot2 & $.40^{* *}$ & .13 & $.77^{* *}$ & - & $.34^{* *}$ & $.53^{* *}$ & .03 & .05 & -.08 \\
5 Controlled mot1 & -.06 & -.15 & $.53^{* *}$ & $.46^{* *}$ & - & $.74^{* *}$ & $-.17^{*}$ & -.11 & $-.26^{* *}$ \\
6 Controlled mot2 & .02 & -.03 & $.71^{* *}$ & $.58^{* *}$ & $.74^{* *}$ & - & $-.19^{*}$ & .03 & $-.19^{*}$ \\
7 Age & .13 & -.03 & .19 & .10 & -.03 & .08 & - & $.45^{* *}$ & .05 \\
8 Tenure & .18 & .23 & .16 & .05 & -.15 & -.08 & $.61^{* *}$ & - & .02 \\
9 Gender & -.02 & $.39^{*}$ & -.05 & .16 & -.19 & -.05 & .15 & .20 & - \\
\hline
\end{tabular}

Notes: Results are based on individual-level data. Correlations above the diagonal: Intervention group; correlations below the diagonal: Control group.

$* p<.05 ; * *<.01$. Because of varying sample sizes, significance levels differ.

Gender: $0=$ Female; 1 = Male; Age and tenure were measured as continuous variables.

measurement occasions. Comparisons of the mean scores of the experimental group on need satisfaction and on the two types of motivation with the mean scores of the control group, by means of $t$ tests, showed no significant differences.

We carried out a series of confirmatory factor analyses (CFAs) in Mplus version 7 (Muthén \& Muthén, 2006) to investigate the dimensionality and measurement equivalence of the measures. A first set of analyses was performed on the pre-intervention data only, for reasons of statistical power. We investigated the dimensionality of autonomous motivation, controlled motivation, and need satisfaction. Separate CFAs were run to investigate the dimensionality of the need satisfaction subscales. The second set of analyses was conducted to investigate the measurement equivalence of the three-factor solution pre- and post-intervention. Scale items were used as indicators of the latent factors. Latent factors were allowed to correlate. We allowed two sets of errors to covary within factor, but not between factors in order to allow for covariance caused by high content overlap, similar wording, and potential subfacets (Cole, Ciesla, \& Steiger, 2007). The results of the analyses are presented in Table 3.

The results show that need satisfaction, and controlled and autonomous motivation can be distinguished from each other and do not constitute a single general factor (upper part of Table 3). The three-factor model outperforms the two-factor model, in which autonomous and controlled motivation are collapsed into one factor, $\Delta \chi^{2}(2)=54.86, p<.001$. The three-factor model also fits the data better than a one-factor model, $\Delta \chi^{2}(3)=399.74, p<.001$. The results further indicate that the one-factor model of need satisfaction fits the 


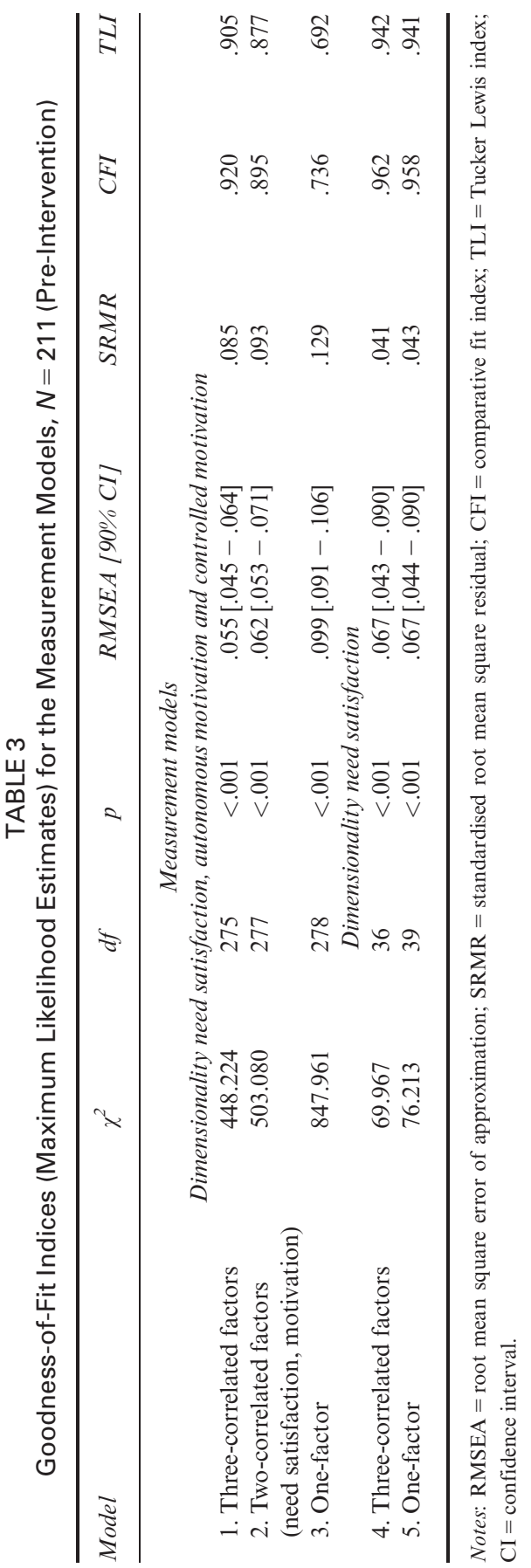

C 2017 International Association of Applied Psychology. 
data as well as the three-factor model, $\Delta \chi^{2}(3)=6.25, p=.10$ (lower part of Table 3). The latter result supports the decision to aggregate the three needs to form one general need satisfaction factor, which was reliable (while this was not always the case for the separate subscales). A test of measurement invariance showed similar structural properties of the measures prior and after the intervention, and partial metric invariance (results available upon request).

The variance decomposition results (based on the unconditional means model, not shown in the tables) indicate that for need satisfaction, most of the variance resided at the occasions-within-individuals level $(63 \%)$, followed by the individual $(23 \%)$ and the team-level $(14 \%){ }^{3}$ For autonomous and controlled motivation, the majority of variance resided at the individual level ( $73 \%$ and $68 \%$ respectively), and to a lesser extent, at the occasions-within-individuals level (22\% and 25\%). The variance associated with teams ( $5 \%$ and $7 \%$ respectively) was considerably smaller.

\section{Test of Hypotheses}

In step 1 of the multilevel regression analysis, we entered time $(0=$ preintervention; 1 = post-intervention), the demographic control variables age and gender $(0=$ female; $1=$ male $)$, and experimental condition $(0=$ control group; $1=$ experimental group $)$ as predictors of need satisfaction, and autonomous and controlled motivation. In this configuration, the intercept refers to the expected overall outcome at the first measurement (T1), which was before the intervention. In addition, the interaction between time and experimental condition was added to the model to test whether teams in the experimental (i.e. intervention) condition show a stronger increase in need satisfaction and autonomous motivation and a stronger decrease in controlled motivation than teams in the control condition.

In step 2 of the analysis, we entered need satisfaction as a time-varying predictor, measured pre- and post-intervention, in the analyses predicting autonomous and controlled motivation. In doing so, we could relate changes in need satisfaction to changes in autonomous and controlled motivation as outlined in our hypotheses. Table 4 presents the results.

\footnotetext{
${ }^{3}$ We also calculated the proportion of variance explained by the different levels of analysis for each of the three dimensions of need satisfaction. The majority of variance resided at the occasions-within-individuals level (autonomy: $80 \%$; relatedness: $59 \%$; competence: $60 \%$ ) and the individual level (autonomy: 15\%; relatedness: 21\%; competence: $31 \%$ ). The remaining variance was associated with teams (autonomy: $5 \%$; relatedness: $20 \%$; competence: $9 \%$ ).
} 


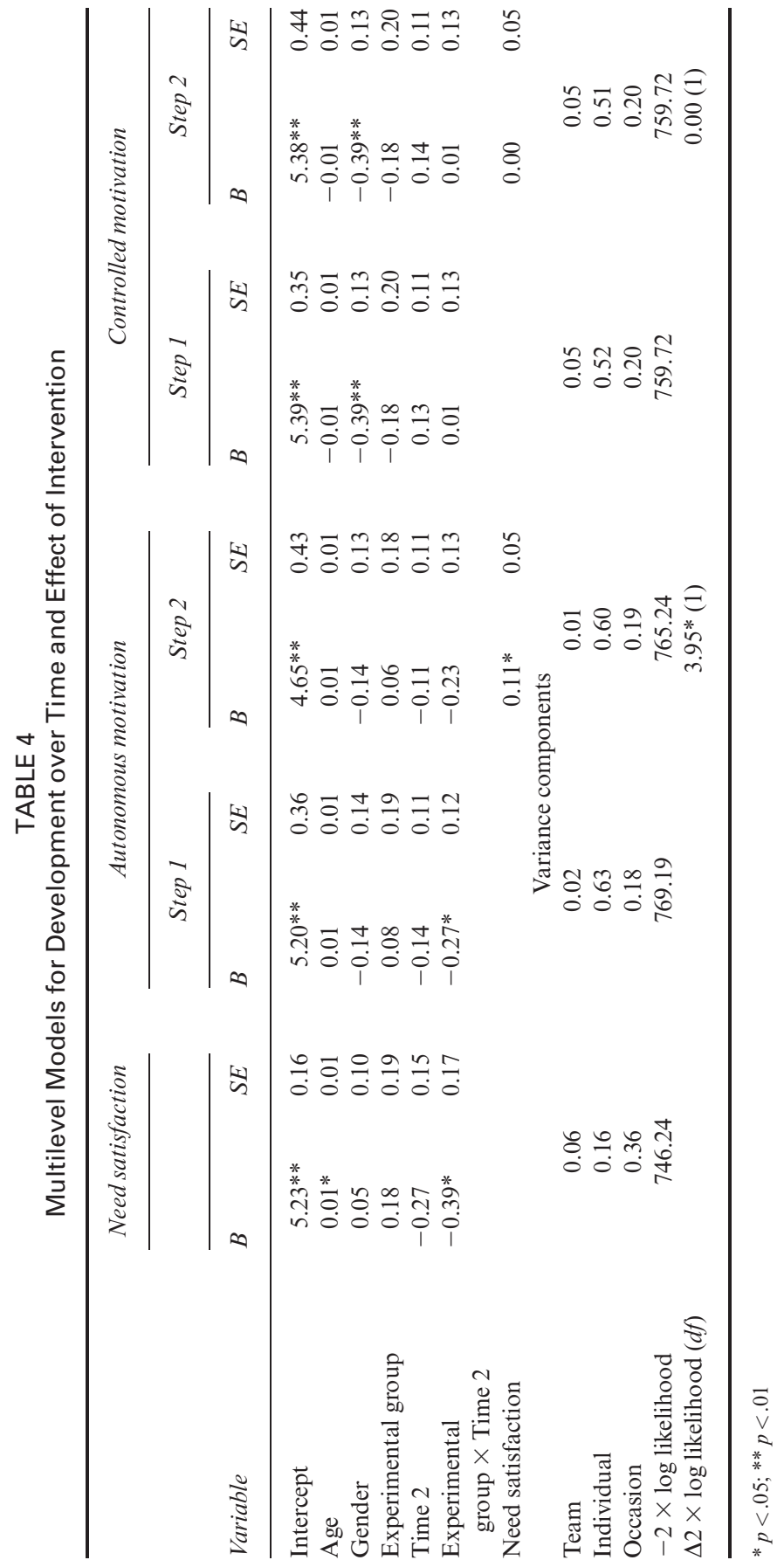

C 2017 International Association of Applied Psychology. 

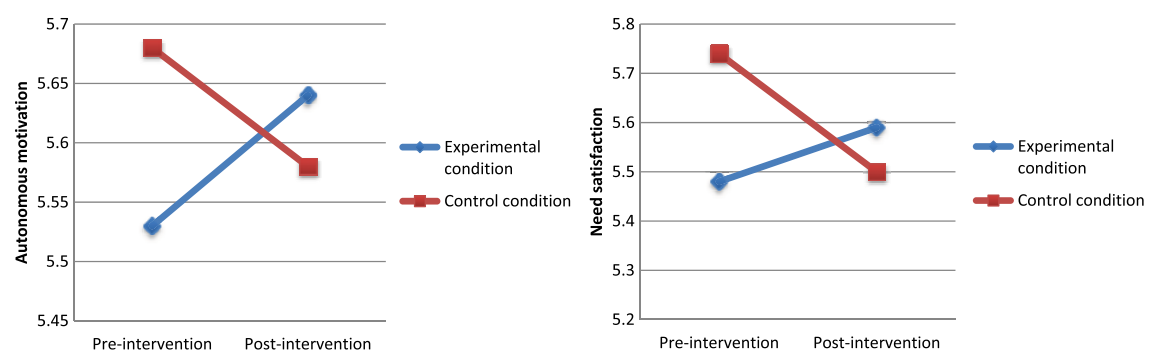

FIGURE 2. Average scores on autonomous motivation and need satisfaction per condition over time [Colour figure can be viewed at wileyonlinelibrary.com]

The interactions reflecting the difference between the experimental group and the control group were significant for need satisfaction and autonomous motivation, but not for controlled motivation (see Table 4, Step 1). The interactive effect of the experimental intervention and time can be viewed more directly in Figure 2, which presents the pre-post intervention scores for need satisfaction and autonomous motivation for the experimental as well as the control group. Although mean scores did not differ between the conditions at the outset and at the end, there was a significant difference in how need satisfaction and autonomous motivation developed. Autonomous motivation significantly increased from pre- to post-intervention in members of the experimental group ( $B=0.14, S E=0.06, p<.05)$, whereas there was a trend to decreases in autonomous motivation in members of the control group $(B=-0.14$, $S E=0.11, p=0.20)$. Members of the experimental group showed a trend to increases in need satisfaction from pre- to post-intervention $(B=0.12$, $S E=0.08, p=.13)$. Those in the control group showed a drop in need satisfaction that was significant at $p=.06(B=-0.27, S E=0.15)$. The effects sizes (beta coefficients) of the interactions were -.25 for need satisfaction and -.17 for autonomous motivation, which are considered small to medium effects (Cohen, 1988).

In step 2 of the regression analysis predicting autonomous and controlled motivation, we added need satisfaction to the model. As is shown in Step 2 of Table 4, need satisfaction was positively related to autonomous motivation, $B=0.10, p<.05$, but not to controlled motivation: Thus, an increase in need satisfaction between $\mathrm{T} 1$ and $\mathrm{T} 2$ was related to an increase in autonomous motivation, but not in controlled motivation. When including need satisfaction into the model the interactive effect of experimental intervention and time on autonomous motivation was no longer significant, $B=-0.2$, ns. We used bootstrapping (5,000 replications) to examine the extent to which need 
satisfaction carries the effect of time*intervention on autonomous motivation. ${ }^{4}$ The bootstrapping results revealed a positive indirect effect of the intervention on autonomous motivation through need satisfaction (point estimate $=.04,95$ per cent bias-corrected $\mathrm{CI}=.01$ to .10 ). About 16 per cent of the total effect on autonomous motivation could be attributed to need satisfaction. Although the indirect effect is relatively small (i.e. approximately five times smaller than the direct effect), it is statistically significant. Collectively, these results are supportive of Hypothesis 1 (effect on autonomous motivation) but not of Hypothesis 2 (effect on controlled motivation).

\section{DISCUSSION}

The present study aimed to provide evidence that team members can satisfy each other's needs and therefore foster each other's autonomous and controlled motivation through participating in a team-based intervention that focused on improving perspective taking, communication and collaboration. We focused on team members as critical resources to improve employee motivation, as organisations cut down on the number of managers while they increasingly rely on teams to do the work (Cordery et al., 2010). As such, team members rather than managers are most likely to be able to make a change (Grant, Gino, \& Hofmann, 2011).

In line with our expectations, members of the teams which participated in the intervention were more satisfied in their basic needs and were more autonomously motivated compared to the members of the teams in the control group, which received no intervention. Moreover, an increase in need satisfaction between $\mathrm{T} 1$ and $\mathrm{T} 2$ was related to an increase in autonomous motivation, such that need satisfaction mediated the effect of the intervention on team members' autonomous motivation. These results support SDT, which suggests that satisfaction of the basic needs for autonomy, competence and relatedness allows employees to see value in their work, identify with the reason for doing their job and/or find enjoyment in doing their job (Deci \& Ryan, 2000).

\footnotetext{
${ }^{4}$ The STATA command for bootstrapping the indirect effect is:
}

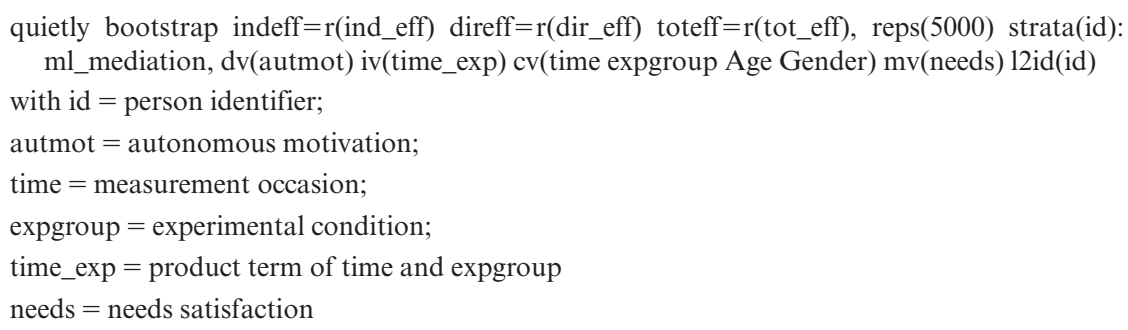


The significant difference in how need satisfaction and autonomous motivation developed among participants in the intervention, compared to participants of the control group, underlines the usefulness of putting team member or colleagues to the fore as a means to increase employee motivation. Participating in the intervention - which aimed to increase perspective taking, communication and collaboration-allowed team members to behave in supportive ways towards each other, more than did the instruction to pay attention to one's communication and interaction as was done in the control group. These results add to the growing literature on SDT by showing that apart from contextual elements, such as organisational factors or job design, and social elements, such as leadership (Van den Broeck et al., 2016), also team members may play an important role in increasing employee motivation. This finding is also important from a methodological point of view. Although several studies aimed to investigate antecedents of need satisfaction and autonomous motivation at work, this is among the first experiment that allows for causal conclusions in the field of work and organisational psychology (Gagné \& Deci, 2005; Ryan \& Deci, 2000).

Notably, participation in the intervention did not result in decreased controlled motivation. From the point of view of SDT, this is peculiar, as SDT would expect that controlled motivation decreases when employees feel satisfied in their needs for autonomy, competence and relatedness. However, to date, several empirical studies - including ours - failed to support this assumption (Van den Broeck et al., 2010a). The lack of firm support for the notion that low need satisfaction should lead to high controlled motivation has led to the suggestion that not need satisfaction, but need frustration is most important in the emergence of controlled motivation (Van den Broeck et al., 2010a). Need frustration is defined as the active thwarting of the feelings of autonomy, competence and relatedness and said to be different and independent from need satisfaction, just like positive and negative affect are different and independent from each other (Bartholomew, Ntoumanis, Ryan, and ThøgersenNtoumani, 2011; Unanue, Dittmar, Vignoles, \& Vansteenkiste, 2014). While low need satisfaction may occur when employees have little options to choose from, cannot use their competencies at work or feel little related, employees may feel frustrated in their needs only when they feel forced to do things that do not align with their values (i.e. frustration of the need for autonomy), they fail to have an impact on the world (i.e. frustration of the need for competence) or they feel rejected or bullied at work (i.e. frustration of the need for relatedness). The current intervention only aimed for team members to enhance each other's need satisfaction, and did not tap into how to decrease need frustration, which may explain why controlled motivation remained unaffected.

As the intervention took place among colleagues within teams, we took these different levels into account in analysing our results. This analysis allowed us to disentangle whether the different aspects of employee motivation 
mostly resides at the within individual level (i.e. is highly volatile), at the individual level (i.e. is a personal characteristic), or at the team level (i.e. is shared among team members). Our results indicate that need satisfaction is a highly fluctuating motivational state, as more than half of the variance in need satisfaction was accounted for by the within-individual level. Autonomous and controlled motivation, in contrast, seem to be more stable, individual characteristics, as more than half of the variance resided at the individual level. Notably, some of the variance in need satisfaction as well as autonomous and controlled motivation is also shared among team members. Team members thus develop shared feelings of autonomy, competence, and relatedness while working and shared an understanding whether work is mainly seen as something important, valuable or fun or whether one feels controlled by external or internal pressures. These results add to the growing body of research, showing that motivation - as defined in SDT - may be contagious among team members (Schreurs, Van Emmerik, Van den Broeck, \& Guenter, 2014). Our design did not permit to gain further understanding of these motivational dynamics at these different levels or to tap into the antecedents and consequences of the aspects of motivation at these different levels, but this would be an interesting route for future research.

Such future research would first need to clarify whether need satisfaction and autonomous and controlled motivation reflect the same processes at the different levels of whether they truly differ from each other. To date, this remains an important question. Within the (relatively small) literature on team motivation, some scholars stress that the shared nature of collective phenomena makes them qualitatively different from individual level constructs, while others regard team motivation as functionally equivalent to individual level motivation (Chen \& Kanfer, 2006; Hu \& Liden, 2015; Li, Kirkman, \& Porter, 2014; Park, Spitzmuller, \& DeShon, 2013). Research tackling this question with respect to SDT's perspective on motivation may shed further light on this issue.

\section{Limitations and Suggestions for Future Research}

This study has several important strengths including the prospective design with measurements prior to and after the intervention and the inclusion of both experimental and control groups. However, we also need to acknowledge some limitations. From a theoretical point, we argued that - through the intervention - team members would be trained in displaying more need supporting behaviours. This seemed to be the case - as team members' need satisfaction increased - but firm support for the mediating role of need supportive behaviour is lacking, as we did not measure team members' evaluation of each other's need supportive behaviour. Future studies could further examine this issue, as well as the boundary conditions for when such training may not result 
in sustained need support and increased autonomous motivation among team members. Team cohesion may be a moderating factor altering this effect, as employees need to be sufficiently close with each other for need supportive behaviours to have their effect (Chen \& Kanfer, 2006).

Methodologically, we were unable to randomly assign teams to the experimental or the control group, as the organisations had a very tight planning for the team interventions: the interventions for the 22 intervention teams needed to be finished at an appropriate time, while for the remaining seven teams (of our control group), the planning allowed to wait with the intervention. However, as we asked the control teams to focus on their communication and they all knew that they too would have the opportunity to participate in the intervention at a later time, we believe they were as motivated as the experimental teams to fill in the questionnaires. Thus, we believe that we managed to make the conditions in the experimental and control conditions quite similar and thus avoided a Hawthorne effect. The relatively small number of teams may however limit the statistical power of our tests.

A second limitation of this study is that no objective outcomes were measured beyond motivation. Further research could, for example, examine whether team interventions supporting the basic needs and autonomous motivation may also lead to positive outcomes such as learning (Roth et al., 2007), job performance (Moran et al., 2012), and work satisfaction (Van den Broeck et al., 2013). Also, as suggested before, such studies may tap into potential consequences at the intra- (e.g. daily fluctuations in affect or performance) and interpersonal level (e.g. engagement, helping behaviour), as well as at the level of teams (e.g. team innovation, team creativity), or even at the organisational level (e.g. financial returns). Such studies would take the research on SDT one step further and examine multilevel consequences of need satisfaction as well as autonomous and controlled motivation.

A third limitation was that we did not continue to assess the durability of changes in team members' need satisfaction and work motivation. The effects of the intervention on need satisfaction and work motivation may be brief, even if comparable interventions suggest that the benefits of supportive training endure once they have been attained (deCharms, 1968; Reeve et al., 2004). Further research could aim to follow up the teams over a longer period of time. Related to this limitation is that we did not measure need satisfaction and work motivation at separate points of time. This would have given us the opportunity to investigate whether need satisfaction actually explains the relationship between the intervention and work motivation, even if this has been the overarching hypothesis that has guided research on SDT and been confirmed in many studies (e.g. Deci \& Ryan 2000).

Finally, our results could not differentiate among the three needs. From a methodological point of view, we could not examine the three basic needs separately as each of the three basic need scales had low internal consistency either 
at Time 1 or Time 2. This may be due to the need satisfaction scale used (Brien et al., 2012), as this scale has not been stringently validated and the content validity of the scale may be improved. In line with this suggestion, a recent meta-analysis questioned other need satisfaction scales for similar reasons (Van den Broeck et al., 2016), and suggested using the Work-Related Basic Need Satisfaction Scale as it has been specifically designed for the workplace and followed a formal scale validation process (Van den Broeck et al., 2010a). However, from a theoretical point of view, it is reasonable to assume that it is unnecessary to differentiate the basic needs as the intervention aimed to train the team members in supporting each of the needs for autonomy, competence and relatedness and each of the needs relates positively to autonomous motivation (Deci \& Ryan, 2000).

\section{Practical Implications}

Despite these limitations, our results have clear practical implications. Our results show that through the intervention, team members can gain a better understanding of how to support each other's needs for autonomy, competence and relatedness, and, hence, autonomous motivation. Our intervention proved to be highly successful, although it was not time consuming and relatively simple to administer. Relying on the same principles as the intervention outlined here, team leaders may thus adopt similar approaches to train team members in perspective taking, communication and collaboration. Our study shows that team members may become more skilled and more effective in supporting each other's needs and autonomous motivation already after five sessions.

It is important to note, however, that our project highly benefited from supportive managers at higher levels. Each of the three organisations highly invests in the performance of their teams, especially of teams with key tasks focused on their core activities. These organisations underscored that increasing motivation is highly valuable to improve organisational performance, but also for the individual employees, as motivation is associated with a host of important positive work outcomes (Gagné \& Vasteenkiste, 2013).

\section{CONCLUSION}

In conclusion, this study demonstrates that a relatively brief, team-based intervention programme may be effective in creating need support among team members such that team members feel more satisfied in their basic needs and report more increased autonomous motivation, compared to participants in the control group. This study underlines the importance of need satisfaction for the success of work motivation programmes. It is among the few to provide experimental evidence and to allow for causal conclusions on the antecedents

(C) 2017 International Association of Applied Psychology. 
of need satisfaction and autonomous motivation at work. Specifically, we put the role of team members to the fore as an increasingly important driver of employee motivation, and pointed out that motivation is a multilevel construct with relevance at the intra- and inter-individual level, as well as at the level of the team.

\section{REFERENCES}

Aelterman, N., Vansteenkiste, M., Van Keer, H., \& Haerens, L. (2016). Changing teachers' beliefs regarding autonomy support and structure: The role of experienced psychological need satisfaction in teacher training. Psychology of Sport and Exercise, 23, 64-72.

Baard, P.P., Deci, E.L., \& Ryan, R.M. (2004). Intrinsic need satisfaction: A motivational basis of performance and well-being in two work settings. Journal of Applied Social Psychology, 34, 2045-2068.

Bartholomew, K.J., Ntoumanis, N., Ryan, R.M., \& Thøgersen-Ntoumani, C. (2011). Psychological need thwarting in the sport context: Assessing the darker side of athletic experience. Journal of Sport \& Exercise Psychology, 33, 75-102.

Baumeister, R.F., \& Leary, M.R. (1995). The need to belong: Desire for interpersonal attachments as a fundamental human motivation. Psychological Bulletin, 117, 497-529.

Brien, M., Forest, J., Mageau, G.A., Boudrias, J.-S., Desrumaux, P., Brunet, L. \& Morin, E.M. (2012). The basic psychological needs at work scale: measurement invariance between Canada and France. Applied Psychology: Health and Well-Being 4, 167-187.

Chemolli, E., Gagné, M., \& Koestner, R. (2012, June). Recurring null results between extrinsic motivation and performance and wellbeing in the workplace: Finding meaning in the void. Paper presented at the Institute of Work Psychology Conference, Sheffield.

Chen, G., \& Kanfer, R. (2006). Toward a systems theory of motivated behavior in work teams. Research in Organizational Behavior, 27, 223-267.

Cheon, S., Reeve, J., Yu, T.H., \& Jang, H.R. (2014). The teacher benefits from giving autonomy support during physical education instruction. Journal of Sport and Exercise Psychology, 36, 331-346.

Cohen, J. (1988). Statistical power analysis for the behavioral sciences, 2nd ed. Hillsdale, NJ: Erlbaum.

Cole, D.A., Ciesla, J.A., \& Steiger, J.H. (2007). The insidious effects of failing to include design-driven correlated residuals in latent-variable covariance structure analysis. Psychological Methods, 12, 381-398.

Cordery, J.L., Morrison, D., Wright, B.M., \& Wall, T.D. (2010). The impact of autonomy and task uncertainty on team performance: A longitudinal field study. Journal of Organizational Behavior, 31, 240-258.

Côté-Lecaldare, M., Joussemet, M., \& Dufour, S. (2016). How to support toddlers' autonomy: A qualitative study with child care educators. Early Education and Development, 27, 822-840. 
DeCharms, R. (1968). Personal causation: The internal affective determinants of behavior. New York: Academic Press.

Deci, E.L., Connell, J.P., \& Ryan, R.M. (1989). Self-determination in a work organization. Journal of Applied Psychology, 74, 580-590.

Deci, E.L., \& Ryan, R.M. (1985). Intrinsic motivation and self-determination in human behavior. New York: Plenum Press.

Deci, E.L., \& Ryan, R.M. (2000). The "what" and "why" of goal pursuits: Human needs and the self-determination of behavior. Psychological Inquiry, 11, 227-268.

Deci, E.L., \& Ryan, R.M. (2008). Facilitating optimal motivation and psychological wellbeing across life's domains. Canadian Psychology, 49, 14-23.

De Cooman, R., Stynen, D., Van den Broeck, A., Sels, L., \& De Witte, H. (2013). How job characteristics relate to need satisfaction and autonomous motivation: Implications for work effort. Journal of Applied Social Psychology, 43, 1342-1352.

Gagné, M., Chemolli, E., Forest, J., \& Koestner, R. (2008). The temporal relations between work motivation and organizational commitment. Psychologica Belgica, 48, 219-241.

Gagné, M., \& Deci, L.E. (2005). Self-Determination Theory and Work Motivation. Journal of Organizational Behavior, 26, 331-362.

Gagné, M., Forest, J., Vansteenkiste, M., Crevier-Braud, L., Van den Broeck, A., Aspeli, A.K., ... Westbye, C. (2015). The Multidimensional Work Motivation Scale: Validation evidence in seven languages and nine countries. European Journal of Work and Organizational Psychology, 24, 178-196.

Gagné, M., \& Vansteenkiste, M. (2013). Self-determination theory's contribution to positive organizational psychology. In A.B. Bakker (Ed.), Advances in positive organizational psychology (Vol. 1, pp. 61-82). Bingley: Emerald Group Publishing.

Gillet, N., Gagné, M., Sauvagère, S., \& Fouquereau, E. (2013). The role of supervisor autonomy support, organizational support, and autonomous and controlled motivation in predicting employees' satisfaction and turnover intentions. European Journal of Work and Organizational Psychology, 22, 450-460.

Gittell, J.H. (2001). Supervisory span, relational coordination, and flight departure performance: A reassessment of postbureaucracy theory. Organization Science, $12,468-483$.

Grant, A.M., \& Berry, J.W. (2011). The necessity of others is the mother of invention: Intrinsic and prosocial motivations, perspective taking, and creativity. Academy of Management Journal, 54, 73-96.

Grant, A.M., Gino, F., \& Hofmann, D.A. (2011). Reversing the extraverted leadership advantage: The role of employee proactivity. Academy of Management Journal, 54, 528-550.

Grant, A.M., \& Wall, T.D. (2009). The neglected science and art of quasi-experimentation: Why-to, when-to, and how-to advice for organizational researchers. Organizational Research Methods, 12, 653-686.

Hox, J.J. (2010). Multilevel analysis: Techniques and applications, 2nd ed. New York: Routledge/Taylor \& Francis Group.

$\mathrm{Hu}$, J.I.A., \& Liden, R.C. (2015). Making a difference in the teamwork: Linking team prosocial motivation to team processes and effectiveness. Academy of Management Journal, 58(4), 1102. 
Julien, E., Senécal, C., \& Guay, F. (2009). Longitudinal relations among perceived autonomy support from health care practitioners, motivation, coping strategies and dietary compliance in a sample of adults with type 2 diabetes. Journal of Health Psychology, 14, 457-470.

Jungert, T., Koestner, R., Houlfort, N., \& Schattke, K. (2013). Distinguishing source of autonomy support in relation to workers' motivation, self-efficacy, and commitment. Journal of Social Psychology, 153, 651-666.

Krull, J.L., \& MacKinnon, D.P. (1999). Multilevel mediation modeling in groupbased intervention studies. Evaluation Review, 23(4), 418-444.

Krull, J.L., \& MacKinnon, D.P. (2001). Multilevel modeling of individual and group level mediated effects. Multivariate Behavioral Research, 36(2), 249-277.

Langdon, J.L., Schlote, R., Melton, B., \& Tessier, D. (2017). Effectiveness of a need supportive teaching training program on the developmental change process of graduate teaching assistants' created motivational climate. Psychology of Sport and Exercise, 28, 11-23.

Le Blanc, P.M., Hox, J.J., Schaufeli, W.B., Taris, T.W., \& Peeters, M.C. (2007). Take care! The evaluation of a team-based burnout intervention program for oncology care providers. Journal of Applied Psychology, 92(1), 213.

Li, N., Kirkman, B.L., \& Porter, C.O.L.H. (2014). Toward a model of work team altruism. Academy of Management Review, 39, 541-565.

Moran, C.M., Diefendorff, J.M., Kim, T., \& Liu, Z. (2012). A profile approach to self-determination theory motivations at work. Journal of Vocational Behavior, $81,354-363$.

Moreau, E., \& Mageau, G. (2012). The importance of perceived autonomy support for the psychological health and work satisfaction of health professionals: Not only supervisors count, colleagues too! Motivation and Emotion, 36, 268-286.

Muthén, L.K., \& Muthén, B.O. (2006). Mplus Version 7 user's guide. Los Angeles, CA: Muthén \& Muthén.

Park, G., Spitzmuller, M., \& DeShon, R.P. (2013). Advancing our understanding of team motivation: Integrating conceptual approaches and content areas. Journal of Management, 39, 1339-1379.

Reeve, J., \& Cheon, S.H. (2016). Teachers become more autonomy supportive after they believe it is easy to do. Psychology of Sport and Exercise, 22, 178-189.

Reeve, J., \& Jang, H. (2006). What teachers say and do to support students' autonomy during a learning activity. Journal of Educational Psychology, 98, 209218.

Reeve, J., Jang, H., Carrell, D., Jeon, S., \& Barch, J. (2004). Enhancing students' engagement by increasing teachers' autonomy support. Motivation and Emotion, 28, 147-169.

Rocchi, M., Pelletier, L., Cheung, S., Baxter, D., \& Beaudry, S. (2017). Assessing need-supportive and need-thwarting interpersonal behaviours: The Interpersonal Behaviours Questionnaire (IBQ). Personality and Individual Differences, 104, 423-433.

Roth, G., Assor, A., Kanat-Maymon, Y., \& Kaplan, H. (2007). Autonomous motivation for teaching: How self-determined teaching may lead to self-determined learning. Journal of Educational Psychology, 99, 761-774. 
Roth, L.M., Markova, T., Monsur, J.C., \& Severson, R.K. (2009). Effects of implementation of a team model on physician and staff perceptions of a clinic's organizational and learning environments. Family Medicine, 41, 434-439.

Ryan, R.M. (1995). Psychological needs and the facilitation of integrative processes. Journal of Personality, 63, 397-427.

Ryan, R.M., \& Deci, E.L. (2000). Self-determination theory and the facilitation of intrinsic motivation, social development, and well-being. American Psychologist, $55,68-78$.

Schreurs, B., Van Emmerik, I.J.H., Van den Broeck, A., \& Guenter, H. (2014). Work values and work engagement within teams: The mediating role of need satisfaction. Group Dynamics: Theory, Research and Practice, 18(4), 267-281.

$\mathrm{Su}$, Y.-L., \& Reeve, J. (2011). A meta-analysis of the effectiveness of intervention programs designed to support autonomy. Educational Psychology Review, 23, $159-188$.

Unanue, W., Dittmar, H., Vignoles, V.L., \& Vansteenkiste, M. (2014). Materialism and well-being in the UK and Chile: Basic need satisfaction and basic need frustration as underlying psychological processes. European Journal of Personality, 28, 569-585.

Van den Berghe, L., Cardon, G., Tallir, I., Kirk, D., \& Haerens, L. (2016). Dynamics of need-supportive and need-thwarting teaching behavior: The bidirectional relationship with student engagement and disengagement in the beginning of a lesson. Physical Education and Sport Pedagogy, 21, 653-670.

Van den Broeck, A., Ferris, D., Chang, C., \& Rosen, C. (2016). A review of selfdetermination theory's basic psychological needs at work. Journal of Management, 42, 1195-1229.

Van den Broeck, A. Lens, W., De Witte, H., \& Van Coillie, H. (2013). Unraveling the importance of the quantity and the quality of workers' motivation for well-being: A person-centered perspective. Journal of Vocational Behavior, 82, 69-78.

Van den Broek, A., Vansteenkiste, M., De Witte, H., \& Lens, W. (2008). Explaining the relationships between job characteristics, burnout and engagement: The role of basic psychological need satisfaction. Work \& Stress, 22, 277-294.

Van den Broeck, A., Vansteenkiste, M., De Witte, H., Soenens, B., \& Lens, W. (2010a). Capturing autonomy, competence, and relatedness at work: Construction and initial validation of the Work-related Basic Need Satisfaction scale. Journal of Occupational and Organizational Psychology, 83, 981-1002.

Van den Broeck, A., Vansteenkiste, M., Lens, W., \& De Witte, H. (2010b). Unemployed individuals' work values and job flexibility: An explanation from expectancy-value theory and self-determination theory. Applied Psychology: An International Review, 59, 296-317.

Williams, G. C., Halvari, H., Niemiec, C.P., Sørebø, Ø., Olafsen, A., \& Westbye, C. (2014). Managerial support for basic psychological needs, somatic symptom burden and work-related correlates: A self-determination theory perspective. Work \& Stress, 28, 404-419.

Zellmer-Bruhn, M. (2003). Interruptive events and team knowledge acquisition. Management Science, 49, 541-528. 